\title{
Do museums foster innovation through engagement with the cultural and creative industries?
}

\section{Chiara Dalle Nogare ${ }^{1} \mathbb{D} \cdot$ Monika Murzyn-Kupisz $^{2} \mathbb{D}$}

Received: 11 July 2020 / Accepted: 16 April 2021 / Published online: 1 May 2021

(c) The Author(s) 2021

\begin{abstract}
The recent narrative on museums as catalysts of innovation and growth considers their relations with other cultural and creative industries (CCIs) to be very important. We argue that most relations museums establish with CCI firms and institutions are unlikely to produce strong positive externalities that make the latter more innovative. To prove this claim, we propose a conceptual framework qualifying projectbased and supply chain relations between museums and CCIs as either strong, moderate, or weak links, according to their potential in terms of knowledge spillovers from museums to CCIs. We apply this taxonomy to data collected from 261 Polish museums. Our findings indicate that strong links are outnumbered by moderate and weak ones. We then suggest that the traditional missions of museums, in particular education and conservation, need to be more thoroughly assessed in terms of their direct and indirect contributions in order to fully capture the impact of museums on innovation in the wider economy.
\end{abstract}

Keywords Museums · Cultural and creative industries · Innovation · Knowledge spillovers

JEL Classification Z11 $030 \cdot$ D62

\section{Introduction}

The role of innovation in fostering economic growth is well established in macroeconomics (Barro and Sala-i-Martin 2003; Romer 1996), and recent contributions highlight that creative professions may play a role in making a nation or a region

Chiara Dalle Nogare

chiara.dallenogare@unibs.it

1 Department of Economics and Mangement, University of Brescia, Via S. Faustino 74/B, Brescia, Italy

2 Institute of Geography and Spatial Management, Jagiellonian University, ul. Gronostajowa 7, 30-387 Kraków, Poland 
more innovative (Cerisola 2019; Rodriguez-Pose and Lee 2020). This is different from saying that the creative sector (the cultural and creative industries, CCIs hereafter) plays a special role in the innovation ecosystem, yet policymakers often translate scholarly evidence into agendas focusing on (variously defined) CCIs (Sternberg 2017). However, while support for CCIs by governments makes sense in many respects (positive effects on well-being and on the attractiveness of local contexts for individuals and firms), it is not to be taken for granted that this is an effective innovation policy. In fact, there is still a lack of robust evidence on both the relative innovativeness of CCIs compared to other industries and the extent to which CCIs foster innovation in the wider economy.

Museums are included in most recent definitions of CCIs (see Sect. 2), and so policy documents have begun including them in agendas for innovation, highlighting the need for them to closely interact with other CCIs. The very presence of interactions is considered as evidence of their being part of the cultural and creative sector, as well as a positive element in terms of the enhancement of the overall impact of CCIs on innovativeness. This has put pressure on museum directors. Traditionally, contributing to innovation has not been part of museums' goals. Their core missions have long been collection, conservation, research, exhibition, and education. ${ }^{1}$ In this article, we aim to highlight that museums do produce positive externalities for the local and regional economy in terms of a higher level of innovativeness, but probably not primarily through their relations with the CCIs.

The claim that museums foster innovation by making the CCIs more creative rests upon the assumption that the links between museums and the CCIs generate strong knowledge spillovers that benefit the latter. In fact, this is how infra-industry relations can spread innovation (Bakhshi and McVittie 2009). A direct way to assess whether this condition is met is to estimate a model where some measure of innovation for the CCI is the dependent variable and the presence of a CCI-museum relation is a covariate. To our knowledge, however, there have been no surveys investigating the innovative products and processes of CCIs in the context of their cooperation with museums. We therefore use an indirect way of verifying whether there are strong knowledge spillovers from museums to CCIs, through the analysis of a unique dataset collected from 261 Polish museums regarding their activities and relations with CCI firms and institutions in the 2017-2018 reporting period.

We first elaborate a taxonomy of museum-CCI cooperation modes, distinguishing between those potentially rich and those likely to be poor in knowledge spillovers. For example, designers who access and get direct inspiration from a museum's collection may be considered an instance of a rich relation (which we define as a strong link). Space rentals are an example of a much poorer relation in terms of the likelihood of knowledge spillovers (weak link). We then apply this taxonomy to the data on Polish museums and conclude that although most museums have relatively frequent exchanges with CCI firms and institutions, weak links greatly outnumber strong ones. This does not conclusively prove, but

\footnotetext{
1 These missions are core in the ICOM definition of a museum. This definition is the subject of an ongoing debate (Sandahl 2019).
} 
certainly suggests that the contribution of museums to innovation through their relations with CCIs is not particularly strong in the Polish context.

More generally, our evidence points to the fact that networking with CCI firms may be overrated for museums because often only the quantitative-rather than the qualitative-dimension of the relation is considered (quality is understood here as a strong potential in terms of knowledge spillovers). Such findings may have direct policy implications and may also help inform future quantitative and qualitative investigations of museum-CCI relations and their impact on CCI innovativeness.

On the other hand, what appears to be an underrated phenomenon is that the traditional core missions of museums may have important consequences in terms of enhancement of innovation in a given national or local context, with positive impacts on economic performance. For instance, the knowledge spillover effects when conservation activities are shared with other institutions (firms, universities) in backward supply linkages are often important. Museums' contributions to innovation through their education mission may be even more significant.

This paper is organised as follows. Section 2 introduces to the literature on the definitions of CCIs and the inclusion of museums into these, as well as innovation and innovation spreading mechanisms. Section 3 clarifies how our contribution relates to this literature and outlines the model we refer to. Section 4 lays out the conceptual framework we propose for classifying the relationships between museums and other CCIs. In Sect. 5, we apply this framework to the Polish case and illustrate the core of our evidence. The subsequent section suggests how the education mission of museums (sometimes implemented in cooperation with CCI firms) may impact innovation, while Sect. 7 presents our conclusions.

\section{CCls, museums, and innovation}

The last three decades have witnessed an increased interest in the links between culture and creativity on one hand and economic growth and development on the other. Cultural and creative industries (CCIs) is one of the concepts that has been elaborated and often discussed in analyses of these connections, in what has been defined as an industry-based approach to the topic (Cerisola 2019).

\section{1 $\mathrm{CCl}$ definitions and museums as a $\mathrm{CCl}$}

Despite the interest in the topic, there is no agreement among scholars and politicians on the very definition of a CCI and which industries should be included. CCIs generally comprise the 'cultural industries', a term with a long tradition and 
Table 1 Museums in CCI definitions

\begin{tabular}{|c|c|c|}
\hline References & CCI sub-sector & Item \\
\hline KEA (2006) & Core arts field-heritage & $\begin{array}{l}\text { Museums, libraries, archaeological } \\
\text { sites, archives }\end{array}$ \\
\hline Throsby (2008) & Other core cultural industries & Museums, galleries, libraries \\
\hline UNCTAD (2010) & Heritage & $\begin{array}{l}\text { Cultural sites: archaeological sites, } \\
\text { museums, libraries, exhibitions }\end{array}$ \\
\hline EC (2010) & Cultural heritage & Cultural heritage \\
\hline Power (2011) & Libraries, museums, heritage & Museums \\
\hline EC (2016) & Archives, museums, cultural heritage & Museums activities \\
\hline DCMS (2016) & Museums, galleries and libraries & Museum activities \\
\hline Statistics Poland (2018) & Cultural heritage & Museum activities \\
\hline KEA (2019a) & Core cultural subsector & Museums \\
\hline KEA (2019b) & Heritage, archives and libraries & Museum activities \\
\hline
\end{tabular}

evolving usage that dates from the 1940s and was redefined in the late 1980s, and the 'creative industries', a term coined in the 1990s in Australia and initially mainly used in the UK context (DCMS 1998; Hartley et al. 2013). ${ }^{2}$ Although the initial DCMS (1998) definition included mainly commercially-oriented sectors such as advertising, architecture, art and antiques, crafts, leisure software, design, film and video, music, the performing arts, publishing, radio, and TV, with time it was broadened to incorporate less profit-oriented subsectors and activities-hence the inclusion of the heritage sector, comprising museums, archives, libraries, and heritage sites (DCMS 2016), in line with the more comprehensive approach to the creative economy proposed by Bakhshi et al. (2015). Such a broad definition of CCIs is also used by the European Commission in its green paper 'Unlocking the potential of cultural and creative industries' (EC 2010: 5-6).

According to Throsby (2015: 59; see also UNCTAD 2010), CCI outputs should share three key characteristics: human imagination and creativity as core inputs; some form of symbolic or cultural content and meaning; connection to intellectual property rights (i.e. potential for copyright). They therefore convey or embody (though to a different extent) both cultural (symbolic) and economic (utilitarian) value (Throsby 2008, 2010). The conceptualisation of the creative industries proposed by Throsby is one of the most cited ones, also because many other studies simply list CCIs and do not properly justify the inclusion/exclusion of any given industry. His 'concentric circles model' (Throsby 2008) comprises 'core creative arts' generating original creative ideas; 'other core cultural industries', which include museums and galleries; 'wider cultural industries' and 'related industries'. A similar approach is adopted by other researchers and institutions who place the creation of original content (i.e. generation of artistic ideas) or drawing on existing

\footnotetext{
${ }^{2}$ It is usually expected either that the two concepts are used as synonyms (Towse, 2003) or that creative industries include cultural industries as a subset (UNCTAD 2010).
} 
creative content (i.e. heritage) at the heart of CCIs (The Work Foundation 2007, 2007; KEA 2019b). According to them, a distinctive feature with respect to creative processes in other industries is the symbolic element embodied in the final output (Galloway and Dunlop 2007).

Although museums were not initially included in studies of either cultural or creative industries, as the definitions broadened they have been incorporated into them (Hartley et al. 2013; Mikić 2012; Throsby 2008). Nowadays, they are generally included as such or under the broader heading of 'cultural heritage'. Table 1 lists a number of scholarly contributions and policy papers doing so.

A summary of potential relations between museums and the other CCIs is presented in the 'Museums and Creative Industries Toolkit' developed by the Northern Ireland Museums Council (2020). For CCI firms, museums can be places of display, dissemination (sale, performance), or production (e.g. filming), as well as sources of creative content and providers of inspiration for such content. In addition, museum employees can be seen as sources of expert knowledge. In other publications, museums are also referred to as potential 'hubs' for creative activities or CCI clusters (OECD-ICOM 2019) or providers of infrastructure for the CCIs (Rectanus 2020). Interactions between museums and CCIs can occur at different stages of the CCI value chain: generation of original creative content, publication, and delivery or distribution of goods and services (KEA 2019b). They can also be discussed from the point of view of the role of museums as aesthetic gatekeepers (Hartley et al. 2013) or gatekeepers in general (Towse 2003), and considering that museums are often public institutions or are heavily subsidised by governments, as a channel through which public policy impacts the CCIs (Hartley et al. 2013).

Even though the links between museums and CCIs have been increasingly mentioned and advocated for recently (OECD-ICOM 2019), they are rarely explored conceptually. Despite general recognition (Simasone et al. 2015; NEMO 2018; OECD-ICOM 2019; Northern Ireland Museums Council 2020) and the establishment of a working group on Museums and Creative Industries within the Network of European Museum Organisations (NEMO) in 2014, both theoretical reflection and empirical evidence is still very limited (Simasone et al. 2015). In particular, the NEMO project provides only limited evidence based on a qualitative study of 24 museums in Latvia.

\subsection{Innovation: its definition and transmission channels involving the CCls}

For the purpose of this paper, we will stick to a strictly economic definition of innovation, disregarding social innovation. It is the very narrative about CCIs that tends to state (but often not prove, see Sect. 2.3) that they are an element that makes an economy more competitive. The Oslo Manual (OECD-Eurostat 2005, 2019) broadens the notion of economic innovation by including not just scientific and technological changes but also organisational, financial, and commercial changes that make firms more competitive through novel approaches to production and markets. The 
broadening of the definition serves the purpose of better covering process innovation and considering not just manufacturing but also the service sector.

The hypothesis that CCIs make a place more innovation-prone is often put forward in relation to either their role as soft location factors, i.e. attractions that the socalled creative class appreciates (Florida 2002), or the fact that CCIs are more innovative than other industries and tend to spread innovation to the rest of the economy.

With reference to CCIs fostering the spread of innovation, Bakhshi and McVittie (2009) argue that the relation between CCIs and other industries must be understood in terms of knowledge spillovers. In particular, they list a number of transmission channels for these spillovers: imitation, worker mobility across industries, projectbased cooperation, and supply chain linkages in which prices do not fully reflect the value of the exchanged good or service. They focus on supply chain linkages and claim that what makes CCIs special is the allegedly important knowledge spillovers they produce specifically through this channel. When CCIs play the role of buyers, knowledge spillovers may stem from the specific requirements they ask of their providers. When they play the role of suppliers, it is the specificity of their services, coming from a very high degree of product differentiation, that matters. The implicit transmission of knowledge accompanying market exchanges with CCIs may help all sorts of firms be more creative in the development of products and processes. Whether this is the case or not is a matter of empirical investigation: firms establishing relations with CCIs should be more innovative.

The detailed account of transmission channels suggested by Bakhshi and McVittie (2009) can also be adopted in the analysis of the positive externalities emerging when CCIs interact with each other. In the concentric model of CCIs (Throsby 2008), positive externalities emanate from the core circle to the others and especially the outer ones (for instance, cultural industries such as publishing and music industries and creative industries such as design and fashion). These positive externalities, justifying the very notion of CCIs as a whole, may be conceived of as knowledge spillovers. To our knowledge, however, they have not as yet been the object of specific empirical analyses.

\subsection{CCls in the literature on innovation and development}

The CCIs allegedly play a special role in the economy, one of the most important reasons being that they are highly innovative (they create new goods and services, hence markets, or organisational solutions) and spread innovation (Petruzzelli and Lerro 2020). They are therefore expected to act as 'conduits for knowledge, innovation and new ideas' (EC 2010: 17) and to be important drivers of technological, economic, and social innovation (KEA 2019a). Moreover, CCIs are said to contribute to the process of adaptation to novelty and the facilitation of change (Potts and Cunningham 2008). Cunningham et al. (2010) suggest this is due to the fact that on the supply side of the market there is complementarity with the ITC sector, while on the demand side of the market CCIs' development is interconnected with the transition to the experience economy (EC 2010). Moreover, recent technological developments have forced some CCI branches to innovate in order to survive in the market. 
For instance, the digital disruption inspired various changes in the music and film industries, including the development of new distribution and business models (Tschmuck 2006; Cunningham et al. 2010; Wikström and DeFillippi 2016).

However, the empirical evidence for the CCI-innovation nexus is at best inconclusive. Sometimes CCIs are found to have an impact on outputs such as employment or growth (Innocenti and Lazzeretti 2019), but this is not evidence, per se, of a relation between CCIs and innovation. In fact, CCIs may also have a role as local attractions for tourists and for creative and non-creative professionals (CCIs as soft location factors: see Florida 2002). ${ }^{3}$ The links between CCIs and innovation require specific empirical assessment using measures of innovativeness as dependent variables. We report here some of the scholarly contributions adopting this approach.

Both Müller et al. (2009) and Lee and Rodríguez-Pose (2014), using survey data from Austria and small and medium-sized enterprises (SMEs) in the UK, respectively, find no evidence that CCIs are themselves particularly innovative. In particular, Müller et al. (2009) use self-reported innovation as their dependent variable, which bypasses the measurement problem affecting many contributions in the innovation literature. This evidence on the whole of CCIs does not exclude that some CCIs are innovative: indeed, there is literature on selected CCI sectors such as the music industry (Tschmuck 2006; Wikström and DeFillippi 2016) and the film industry (Cunningham et al. 2010) indicating that they are highly innovative. A possible reconciliation of these contrasting findings may come from the analysis of innovation in other CCI subsectors that may underperform in this respect.

As for the tests of whether CCI interaction with other economic sectors induces the latter to be more innovation-prone, Bakhshi and McVittie (2009) find a positive conditional correlation between CCIs and innovation in an economy: firms that innovate more are in economic sectors that purchase more goods and services from the CCIs. Yet, the direction of causality in this relationship cannot be detected through their empirical strategy. It may be that CCI inputs drive innovation, but it is equally possible that the firms requiring more CCI inputs use those goods/services to promote their innovation, the primary determinants of which lie elsewhere (think of advertising services, for instance). Bakhshi et al. (2015) deal with causality in a more appropriate way. The authors analyse a British business-to-business (B2B) voucher scheme meant to stimulate creative partnerships as a natural experiment. Their dependent variables are SMEs' self-reported introduction of an innovation 6 and 12 months after they received a voucher, and in a second model, the intention to introduce an innovation in the future. Treated firms did show some different behaviour (but not intentions) in the very short run, but after 12 months treated and untreated firms were not statistically different. This evidence on causal effects is especially modest if one considers that the authors refer to the UK definition of CCIs, which also includes software and computer services. Müller et al. (2009) use survey data to identify the determinants of the probability of a CCI contributing

\footnotetext{
3 This is especially true for CCIs that qualify as amenities. However, recent empirical evidence shows that cultural amenities are not very effective as soft location factors for professionals (Cerisola 2018; Van Heerden and Bontje 2013).
} 
to innovation in other firms, and they include dummies for the different CCI categories. ${ }^{4}$ Arts-related CCIs and architecture have a significantly negative sign (the reference category is engineering). Apparently, the overall positive effect of CCIs masks very different levels of performance, with software and advertising having the most prominent role in fostering innovation in other sectors. Considering data from 187 Italian firms, Santoro et al. (2020) find that the share of sales derived from new products and services, a proxy for innovation performance, depends on a variable capturing the importance attributed by firm CEOs to informal relations with the CCIs (here including software). However, it is not to be taken for granted that the value of this variable actually captures the frequency and quality (or even the existence) of such relations. Using data on Italian provinces, Cerisola $(2018,2019)$ investigates the determinants of economic, artistic, and scientific creativity, which she measures respectively as the percentage of trademarks, highly specialised employees in arts and highly specialised employees in science over the population. The relative impact of CCIs on the economy (here not including museums and measured 10 years earlier) is not a significant driver of creativity when spatial autocorrelation is accounted for.

In spite of little evidence in favour of the idea that CCIs as a whole are more innovative and spread innovation more than other industries, many still find the narrative about the CCI-innovation nexus convincing and interest in the topic is not diminishing. Making reference to the innovation literature of the Schumpeterian tradition, some argue that the special role of CCIs could derive from their being part of the innovation system that drives the growth of the knowledge process underpinning economic evolution. In other words, they are a higher-order system operating not within but on the economic system, and it is hard to operationalise this issue (Potts and Cunningham 2008). Alternatively, it may well be that the extant empirical evidence considers highly imprecise measures of innovativeness.

\section{Outline of the present investigation}

The focus of this article is on the role museums play in fostering innovation in CCI firms and institutions they have ties with. It is their potential in terms of knowledge spillovers we want to investigate. Throsby (2010: 95) himself suggests that there is a need to pay more attention to within-CCI cooperation:

'ways in which firms in the cultural industries interact with other businesses... via the supply and demand for goods and services that are exchanged between them (...) Similar interactions occur amongst the cultural industries themselves. Such interrelationships are of course characteristic of all industries in the contemporary economy; interest in the cultural industries might focus on

\footnotetext{
4 Their definition of CCIs is peculiar as they only consider for-profit companies and they include engineering and consulting.
} 


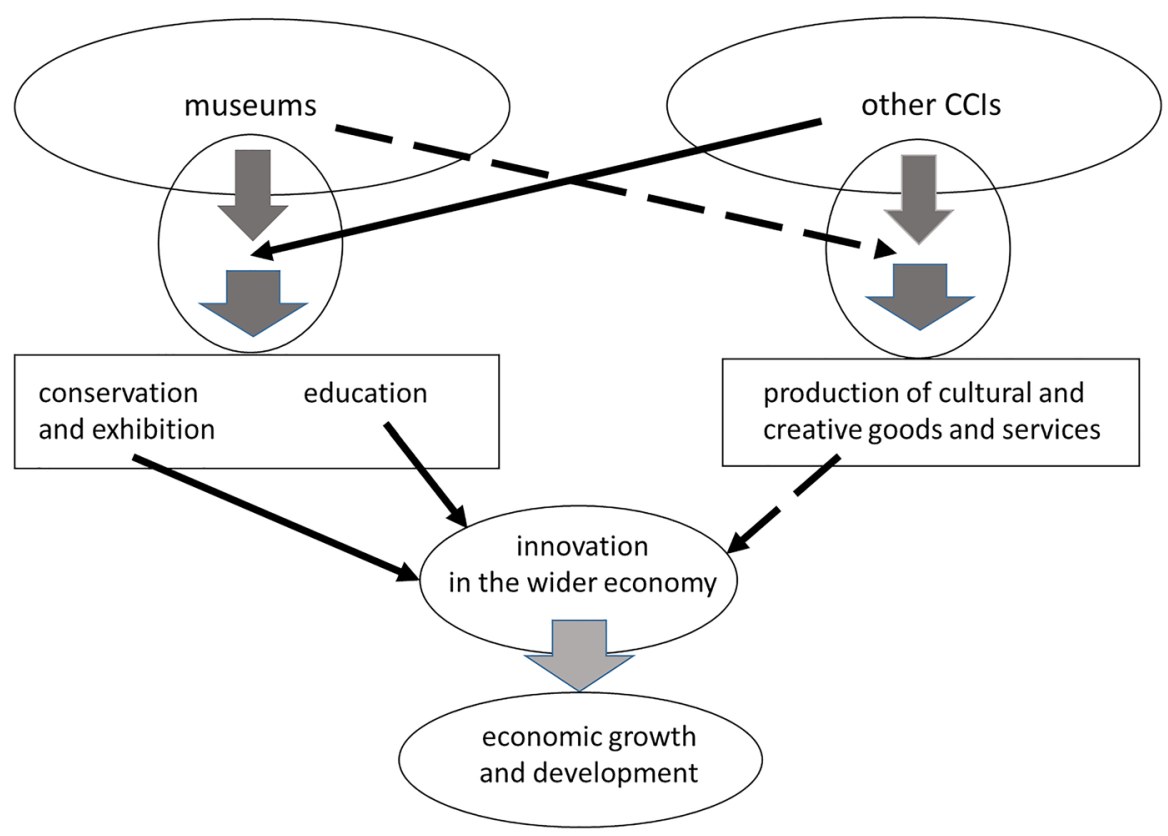

Fig. 1 Positive production externalities between museums and the other CCIs. Source: authors' own elaboration

how far-reaching and how significant these interdependencies are' (Throsby 2010: 95).

We follow Throsby's (2008) conceptualisation of CCIs, and we therefore define the CCIs as comprising the following industries: contemporary visual arts and photography; performing arts; music (both artists and the industry); the book and publishing industry; the radio, TV and film industries; internet portals and the press; the advertising industry; design and architecture; fashion. We also include artistic crafts and toys as part of design.

We consider the cooperation between museums and CCIs from the point of view of the innovation processes generated or enhanced as a consequence of this. Figure 1 illustrates our conceptual framework.

The vertical ovals represent museums and CCI production functions. The dashed arrow represents the potential knowledge spillovers from museums to the other CCIs, making the latter more innovative and hence producing more added value and a competitive advantage. The solid arrow refers to the positive externalities generated by the other CCIs and benefitting museums.

Most of the narrative on the relations between museums and CCIs has been focusing on the dashed arrows. It often tends to overlook the circumstance that what makes the associated interactions relevant is not their existence per se but the associated spillovers, if present. Accordingly, our first aim in this paper is to 
verify whether exchanges between museums and other CCIs are characterised by strong positive externalities making the latter more innovative. A second point we want to highlight is that museums' contributions to innovation through their traditional core missions should not be overlooked and should be investigated in greater depth in the future (De Miguel Molina et al. 2019a).

In order to address our first point, we classify the broad range of relations a museum can establish with other CCIs according to the potential they have in terms of knowledge spillovers. We neither have data on innovation activities by CCIs that have contacts with museums nor on their innovation output (innovative products or processes), so we cannot devise a quantitative empirical strategy that actually assesses the impact of a relation with a museum on a cultural or creative firm's innovativeness. Rather, our proposal of a taxonomy for the relations between museums and CCIs serves the purpose of revealing that it is not the presence of a relation per se that matters, but rather its potential in terms of knowledge spillovers. In fact, if this were not so, one could say that the relations between all types of firms and institutions would be relevant for innovation. We should focus on relations with a higher potential in terms of innovation enhancement; however, it may well be the case that these constitute a small minority. Application of our taxonomy to the data collected from Polish museums illustrates one of such cases.

\section{Assessing museum relations with CCls: a conceptual framework}

Given the essential role knowledge spillovers play in making the relationship between museums and CCIs fruitful in terms of innovativeness, it is important to assess the actual existence of such spillovers. We focus on two of the transmission channels identified by Bakhshi and McVittie (2009): project-based cooperation and supply chain linkages, as imitation and qualified worker mobility between museums and other CCI firms and institutions are not strong, given the high specialisation characterising museum operations.

As stressed earlier, the very presence of project-based cooperation or a supply chain link is not in itself proof of knowledge spillovers. Rather, it is the quality of links that makes them more likely. Quality is understood here in terms of the type or characteristics of such relations that make them likely to generate innovations. We hence consider two aspects of the links between museums and other CCIs that indicate a greater potential for such positive externalities to occur, namely the frequency and nature of interactions.

First of all, museums may interact with designers, theatres, TV producers, advertising companies, and other CCIs occasionally or on a permanent basis, and a permanent relation is often more likely to entail the transmission of ideas and competences. Frequency is a rough indicator, however, because it is a (perhaps) necessary but not sufficient condition for positive externalities to occur.

Secondly, if information on the nature of the contacts between a museum and a CCI firm or institution is available, it is possible to categorise them according to their likelihood of entailing knowledge spillovers fostering innovation. Whether 
or not a museum is, for a CCI firm, just another supplier/client counterpart or a unique and irreplaceable partner making it more innovation-prone depends on the exchanged service. This is what we want our taxonomy to capture.

Symbolic meanings are among the discriminatory elements many authors cite as essential in defining creative goods and hence creative industries (Galloway and Dunlop 2007; Throsby 2015). The transmission of symbolic meanings (conducive to new creation) may then be exactly what makes it impossible for other counterparts to deliver the same as a specific museum in the context of infra-industry relations. The knowledge spillovers stem from access to museum collections and/or from the knowledge possessed and passed on by museum staff.

On the other hand, if a CCI company can easily exchange with an alternative partner to obtain the same type of goods/services it gets from a museum, the relationship between it and the museum is likely to be poor in knowledge spillovers. In this case, in fact, the object of the exchange does not have anything to do with what makes a museum unique, i.e. its collection.

We therefore propose the following definition:

Definition 1 (Strong museum-other CCI firm link) A relation between a museum and a CCI firm or institution is defined as a strong link if there are important knowledge spillovers from the former to the latter. These spillovers are generated by the transmission of symbolic meanings, more often than not stemming from expertise and knowledge about the particular museum collection. The knowledge spillovers increase the probability for a cooperating firm or institution to innovate, i.e. to generate either of the following: (a) new creative content; (b) an innovative reinterpretation of existing creative content; c) new ways of conveying creative content.

An example of forward supply chain linkages rich in potential spillovers is the case of museums making their collections available as inspiration for designers or artists (for instance, through an artist-in-residence programme). An example of a strong link in the backward supply chain is the case of museums asking an architect to design an extension of its premises. The architect will probably have a chance to access the museums' archives and deepen their knowledge of the collection the extension will host, as well as of museum functions in general. These are cases in which the contact with a museum entails a potential increase in creativity for a CCI firm and/or the addition of unique content to the goods/services it produces now and in the future.

Our definition of a moderate museum-other CCI firm link is as follows:

Definition 2 (Moderate museum-other CCI firm link) A relation between a museum and a CCI firm or institution is defined as a moderate link if there are some knowledge spillovers of the type described in Definition 1 from the former to the latter, but they are less likely and not as relevant for the improvement of the firm's innovativeness.

The definition of a weak link thus follows: 


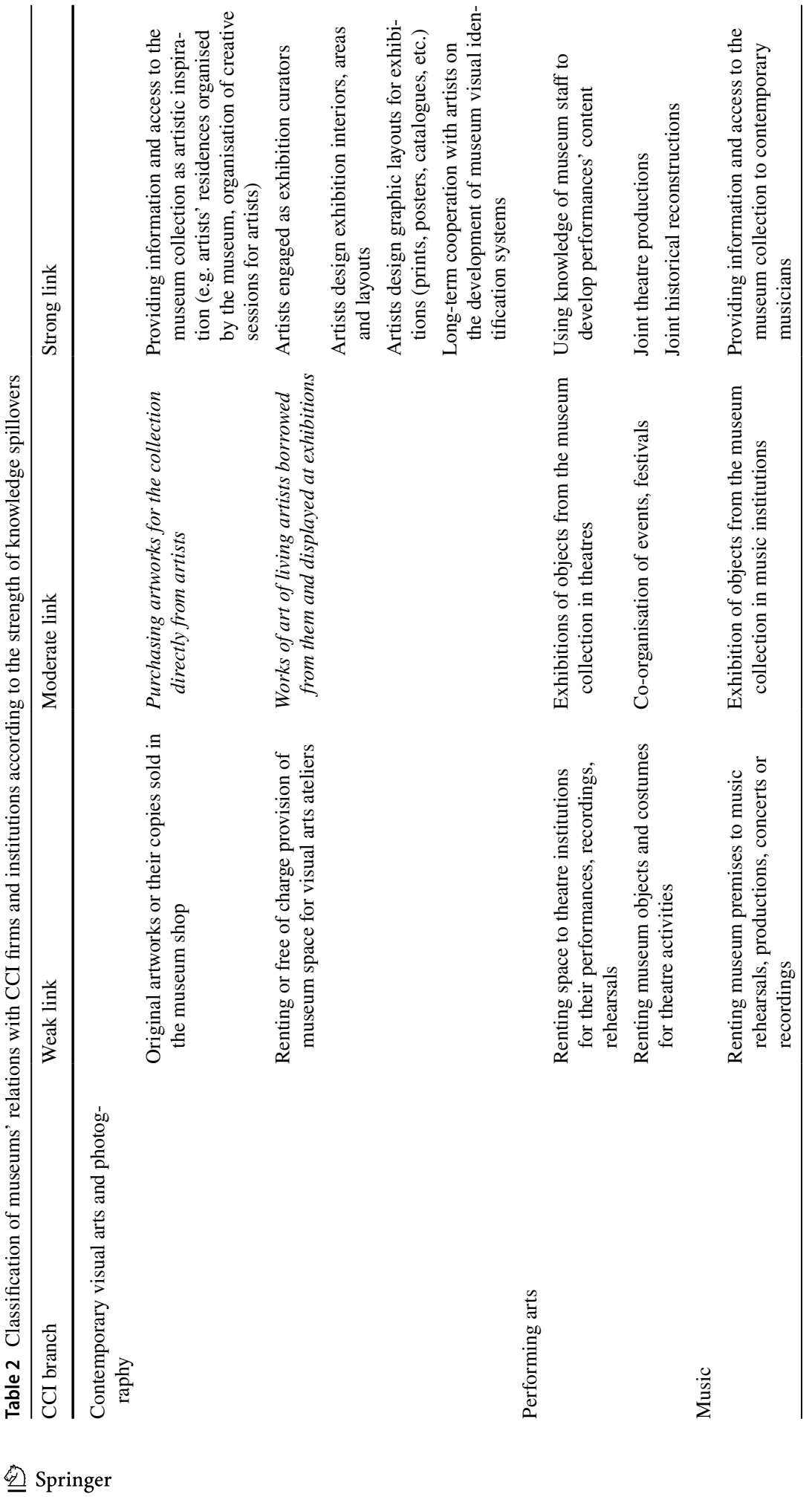




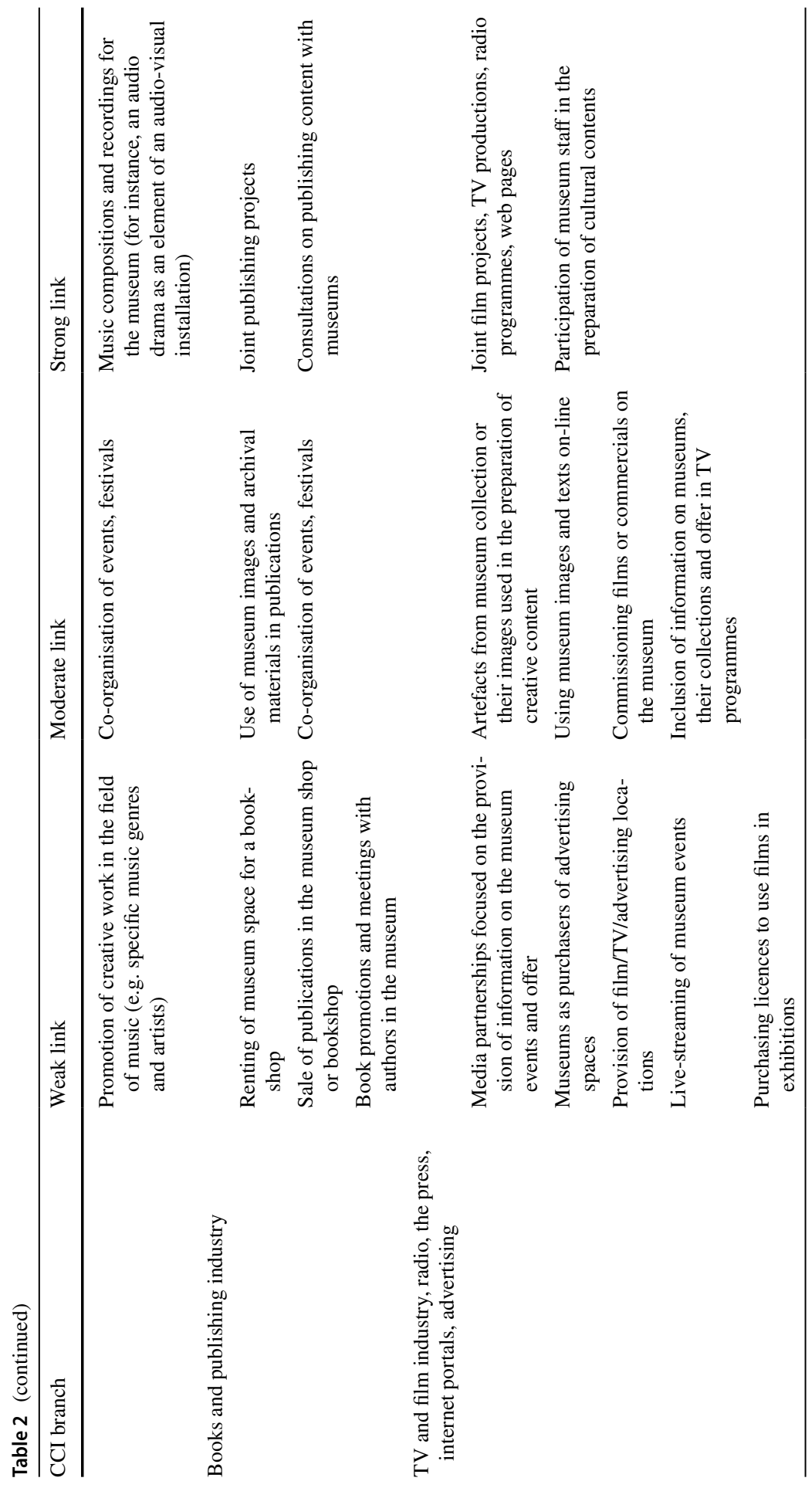




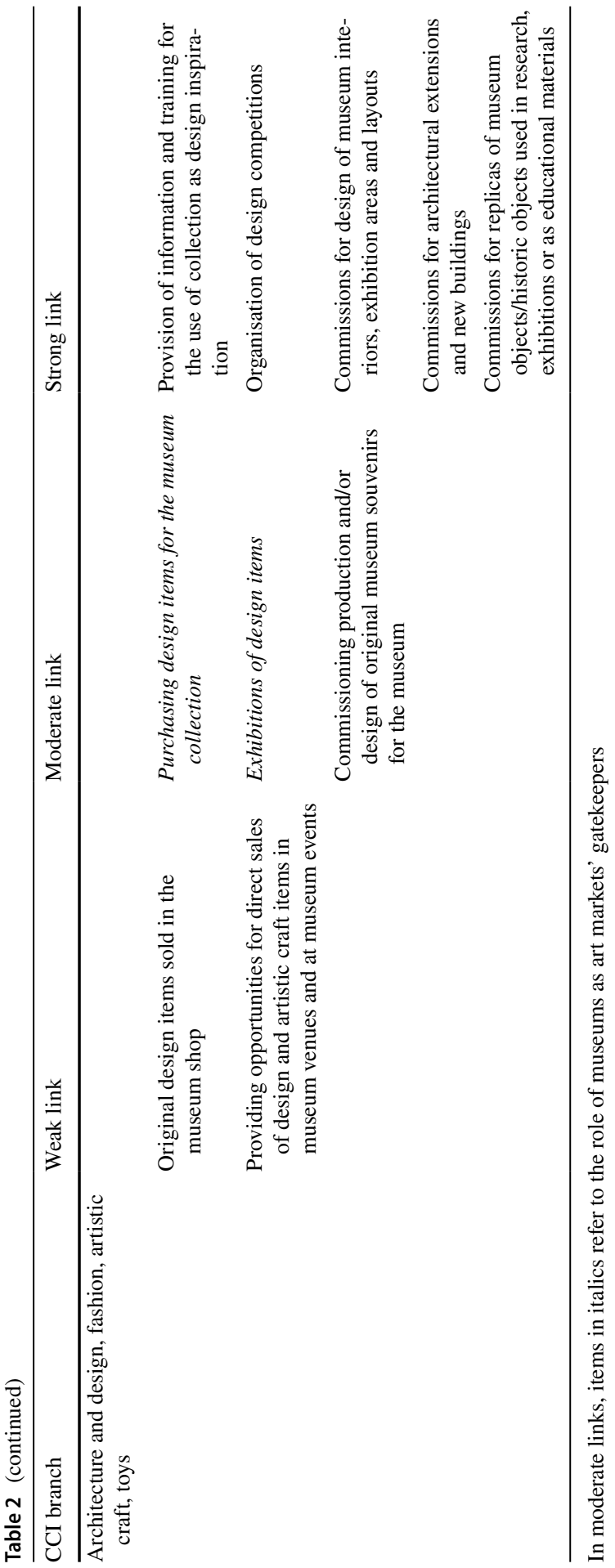


Definition 3 (Weak museum-other CCI firm link) Cooperation between a museum and a CCI firm or institution may be considered as a weak link if there are very few or no knowledge spillovers from the former to the latter, and hence no or very little effect on the CCI firm's behaviour and choices.

An example of forward supply chain linkages likely to be poor in spillovers is, for instance, museum space rentals - provision of museum space that does not involve other closer forms of cooperation between a museum and its tenant. Indeed, a CCI company may rent prestigious historic locations from a number of other providers (e.g. private owners of historic buildings and sites). An example of backward supply chain linkages poor in knowledge spillovers is a contract for the provision of advertising space, or the function of museums as places of sale for artworks, design, and artistic craft items produced regardless of cooperation with the museum and with no reference to the museum collection.

Table 2 presents a tentative classification of relations between museums and other CCIs according to their potential in terms of the enhancement of the latter's creativity, hence distinguishing between strong, moderate, and weak links. ${ }^{5}$ The list of exchanges in each category is not exhaustive: the types of museums are so numerous and some of them are so specialised that it is impossible to take account of all idiosyncratic relations they engage in. Rather, this is a grid classifying the (potential) partnerships with CCIs that a standard museum is likely to set up.

In line with the above, weak links are very unlikely to inspire the transmission of symbolic meanings. Most of the weak links involve hosting (either for free or for money), ${ }^{6}$ purchasing already produced goods and services for the museum, and buying advertising space. This is unlike most of the strong links, which involve the coproduction of creative content and circumstances in which artists and/or CCI staff have long and deep exposure to the collection and interact closely with the museum staff.

In the moderate category, we place a miscellany of activities such as lending items from the museum collection to other cultural institutions and the co-organisation of events such as festivals, assuming that there are some positive externalities stemming from the contact between museum staff and the employees of CCI firms and institutions. The category also includes relations in which a museum plays a role as an art market gatekeeper. We explain the choice of categorising these specific exchanges as moderate links in the Appendix. In general, these types of cooperation are likely to produce knowledge spillovers entailing transmission of symbolic meanings with some probability, but not a very high one.

Table 2 may be interpreted in two different ways. On the one hand, it offers a reading of museum relations with the other CCIs in terms of their potential for increasing CCI innovativeness. It is a positive analysis and may be useful to scholars who wish

\footnotetext{
5 Some museums are not just institutions focused on conservation and exhibition but enlarge their scope of action by including in their operations activities such publishing books and producing content. However, this is not the rule, and we abstract here from these non-core activities.

6 Dalle Nogare and Scuderi (2020) find that, in Italy, renting spaces is a museum policy aimed at generating revenue more than anything else, and in fact private museums, which rely less on public subsidies, adopt this strategy more often.
} 
to assess the contribution of museums to the innovativeness of the CCI firms engaging with them. In fact, it invites them to consider the right explanatory variable: what matters is not how many relations the investigated CCIs have with museums, but the number of strong links. On the other hand, the table may also be referred to by museum directors in normative terms. A contribution to CCI innovativeness may be a feasible museum mission, but only if certain types of cooperation are established.

\section{Evaluating museum relations with $\mathrm{CCls}$ in terms of the potential for $\mathrm{CCl}$ innovation: the Polish case}

Despite the growing interest in the economic impact of museums and their links with the CCIs (NEMO 2018), to the best of our knowledge there are very few publications dealing with this issue comprehensively and in depth. This may be due to a lack of detailed statistical data - a Latvian qualitative pilot study of a small number of museums may be regarded as an exception (Sīmansone et al. 2015). This is why the data from the museum survey conducted by the Polish National Institute for Museums and Public Collections (NIMOZ) that we use here, which is based on a much larger sample of museums, is of particular importance. ${ }^{7}$ The survey was inspired by recent recommendations on the analysis of the impact and economic relevance of museums (OECDICOM 2019). ${ }^{8}$ The information provided to NIMOZ by 261 museums in Poland with respect to the 2017-2018 reporting period includes responses to detailed questions on cooperation between museums and the CCIs. ${ }^{9}$

\footnotetext{
7 For several years, NIMOZ has recognised the need for more detailed and comprehensive statistical data on museums in Poland. In 2013, it started its 'Museum Statistics' programme, parallel to standard surveys conducted by Statistics Poland (the National Statistical Office).

8 In Poland, there are case studies of selected museums and analyses of general data on museum employment, income, and spending (Murzyn-Kupisz 2017) but a dearth of deep analyses of processes, structures, or relations between museums and other institutions and firms (Murzyn-Kupisz et al. 2019). As for the CCIs, there are standard statistical data on value added, employment, and the number of firms (e.g. Kasprzak 2017; Statistics Poland 2018), and on selected locations and CCI subsectors (Chapain and Stryjakiewicz 2017).

9 The 261 museums include 203 single-site institutions and 58 multi-site ones. Some (20\%) are located in the five Polish metropolitan areas (over 500,000 inhabitants), 20\% are in large cities (100,000-500,000 residents), 44\% (two in five) are in towns and small municipalities (10,000-100,000 residents), and 16\% in very small municipalities (up to 10,000 residents). Thus, both urban and non-urban contexts are covered. This makes the sample representative of the entire population of Polish museums. This representativeness also holds for ownership type. The museums in the survey are mainly public institutions: about $8 \%$ are owned and managed by the central government, $70 \%$ are local, county, or regional government institutions, $9 \%$ are run jointly by different governments, and $7 \%$ are museums owned and run by NGOs. Our sample also covers a vast range of collection types. History museums represent $15 \%$, ethno-anthropological museums 7\%, specialised collections $6 \%$, and science and technology museums $5 \%$ of the sample. The majority $(60 \%)$, however, declare having an interdisciplinary profile, including the arts. In the Polish context, in fact, it is common to assign to a single institution the management of different types of collections.
} 


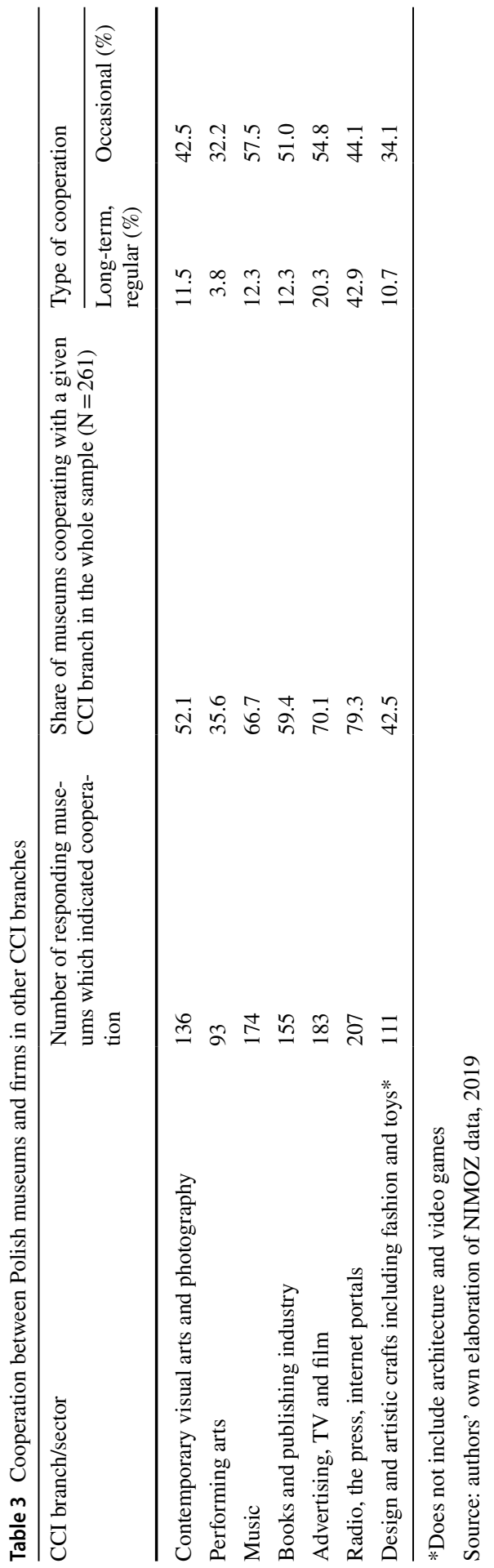


Polish museums that participated in the above-mentioned survey report a variety of engagements with different branches of the CCIs (Table 3). ${ }^{10}$

The most frequent partners of museum institutions are firms representing the advertising, film, and TV industries and radio, the press, and internet portals. Cooperation with such firms was indicated by over $70 \%$ of museums that took part in the survey. Two-thirds of museums pointed to cooperation with the music industry and three out of five with the book and publishing industry. Slightly over half of institutions cooperate with the contemporary visual arts sector. Two in five museums report cooperation with the design and artistic crafts sector and over one-third with the performing arts sector.

However, these relatively high shares must be read with caution. Indeed, Table 3 also illustrates the distinction between regular and occasional cooperation. ${ }^{11}$ In all cases, occasional cooperation with both local and non-local firms and creative professionals dominated. The only relation with a relatively high percentage of regular cooperation is that between museums and radio stations, the press, and internet portals, yet here occasional exchanges dominate too.

Even more importantly, the fact that Polish museums cooperate with the CCIs does not necessarily mean that their links are complex and conducive to innovation through knowledge spillovers. Hereafter, we illustrate evidence confirming this, derived by applying the taxonomy in Table 2 to our dataset. Each of the following figures refers to the relation between museums and a different CCI subsector, and percentages are shares over the whole sample.

Before illustrating these figures, it is necessary to clarify that in many instances, a museum-CCI firm relation has many facets that can be classified in different ways. Think, for instance, of an artist-in-residence programme: it often entails both exposure to the museum collection (possibly mediated by the expertise of museum staff) and the use of workspaces within the museum. The first instance is a strong link, and the second is a weak one. In the survey, museums were asked to choose out of a menu of relations, and an 'other' category was also present in which museums could write unmentioned items. We believe that reputational incentives led museums to classify their relations with the different CCI subsectors so as to draw attention to their cultural programmes. Therefore, it is highly unlikely that, say, a museum with an artist-in-residence programme classified it as rental of spaces. Similarly, any relation with advertising companies involving the transmission of symbolic meanings is not likely to have been classified as the mere purchasing of advertising space, even if a commercial aim was present. In other words, we consider it unlikely that weak links are inflated by the misallocation of items by the respondents to the survey.

\footnotetext{
10 The survey does not include questions on cooperation with companies in the architecture and computer games subsectors.

11 The survey asked museums to categorise their relations with each CCI subsector as either occasional or regular. It may well be that a museum cooperated with the press regularly and with internet portals occasionally, for example - this is counted as 1 in the nominator of both columns 4 and 5 in the row corresponding to 'radio, press, and internet portals'. That is why the percentages in the last two columns do not sum up to give the percentage in column 3 in the same row.
} 


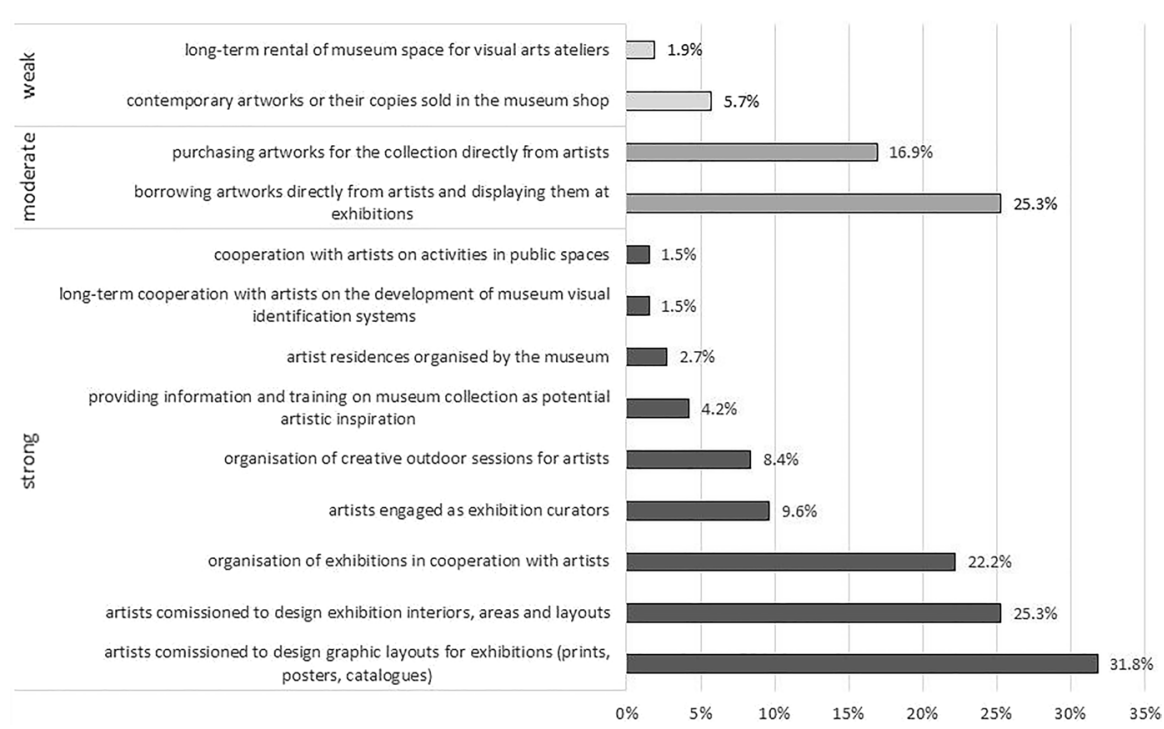

Fig. 2 Main forms of cooperation between Polish museums and the photography and visual arts sector. Source: authors' own elaboration of NIMOZ data, 2019

\subsection{Contemporary visual arts and photography}

We start with the visual arts, for which-taking into account that most museums in the sample have an arts collection - we expect relatively higher engagement (i.e. more diverse and more complex forms of exchanges, mainly with visual artists, who in our conceptual framework can be considered as SMEs) (Fig. 2).

Contrary to expectations, the share of museums involved in this type of interaction is, in general, not very high. However, in line with our expectations, strong links dominate, though the strongest ones among them are not so common. There are very few weak links. The role of museums as intermediaries in the sale of artworks or providers of space is rare (only 5.7\% of museums offer opportunities to purchase contemporary artworks in the museum shop, and only $1.9 \%$ of museums rent space for artist ateliers). Exchanges connected with the gatekeeping role of museums, classified as moderate links, are present but not so important. Only one in six museums admits to purchasing artwork for their collections directly from artists, and one-fourth borrows artworks directly from artists and display them in exhibitions. The two most frequent forms of strong links are possibly the least rich in the category in terms of knowledge spillovers: about one-third of museums report that they commission artists to design graphic materials for exhibitions; one-fourth of museums commission artists to design museum and exhibition interiors, areas, and layouts. We then find joint exhibition projects (one in five museums) and inviting artists to act as exhibition curators (one in ten museums). This cooperation is beneficial to artists in terms of a broader knowledge of museum collections, possibly a source of artistic inspiration. Other strong links between museums and the visual arts sector are rarer. These include the organisation of creative sessions, workshops, 


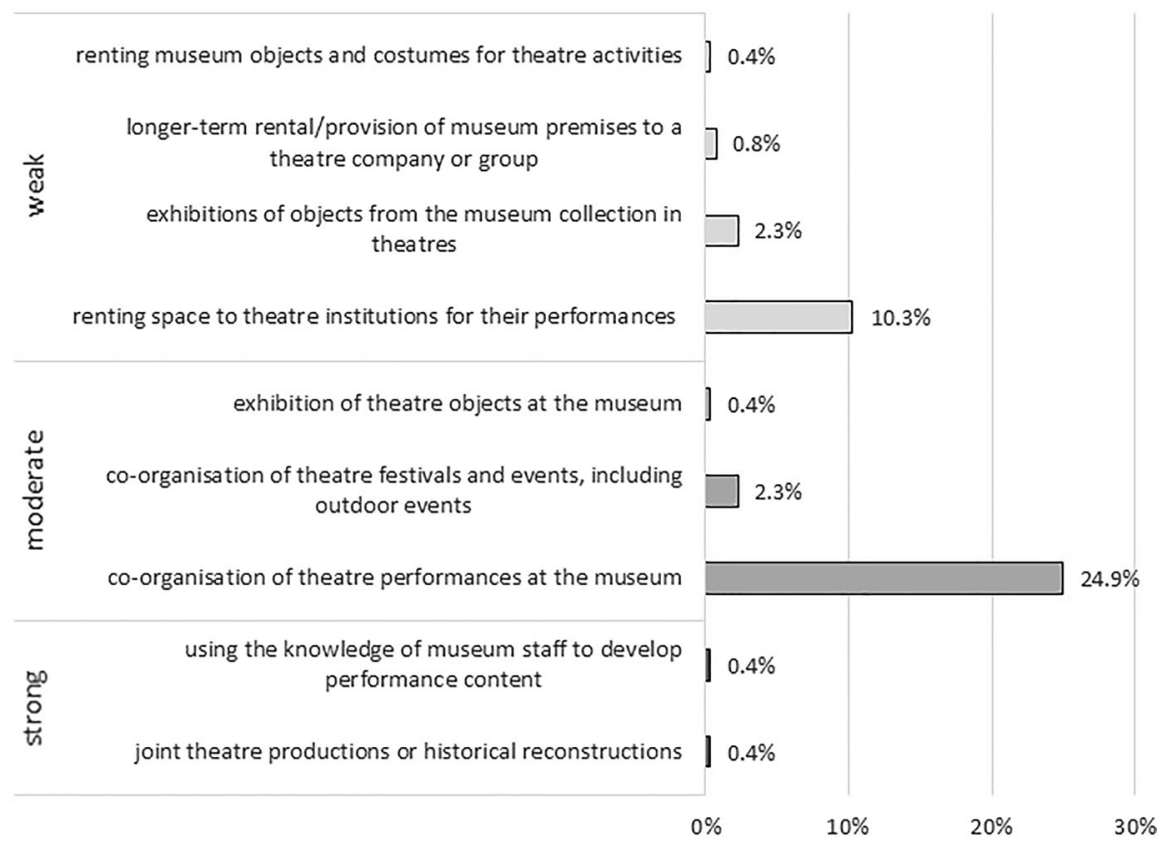

Fig. 3 Main forms of cooperation between Polish museums and the performing arts sector. Source: authors' own elaboration of NIMOZ data, 2019

or competitions for artists (8.4\% museums), direct encouragement given to artists to get inspired by museum collections or venues by providing specialist training and organising workshops and information sessions on museum collections (4.2\% museums), or organising artist residences at museums (2.7\% museums).

\subsection{Performing arts}

Cooperation between museums and the performing arts sector in Poland is neither frequent, strong, nor complex (Fig. 3).

The most frequent forms of cooperation are the co-organisation of performances at museums (one-fourth of respondents) and renting museum space for theatre performances, shows, and recordings (one in ten museums) or rehearsals (two museum institutions that participated in the survey). These forms of cooperation are meant for the promotion and delivery of existing performing arts content and for making the museum more attractive to diverse audiences rather than for the exchange of knowledge or provision of inspiration for the performing arts sector. Other forms of cooperation are extremely rare, in particular those which could enable interesting knowledge spillovers such as joint theatre productions or specialist consultations with museum staff. We conclude that if Polish museums engage with the performing arts sector, they most often have aims other than offering opportunities for innovation to the institutions working in the field. 


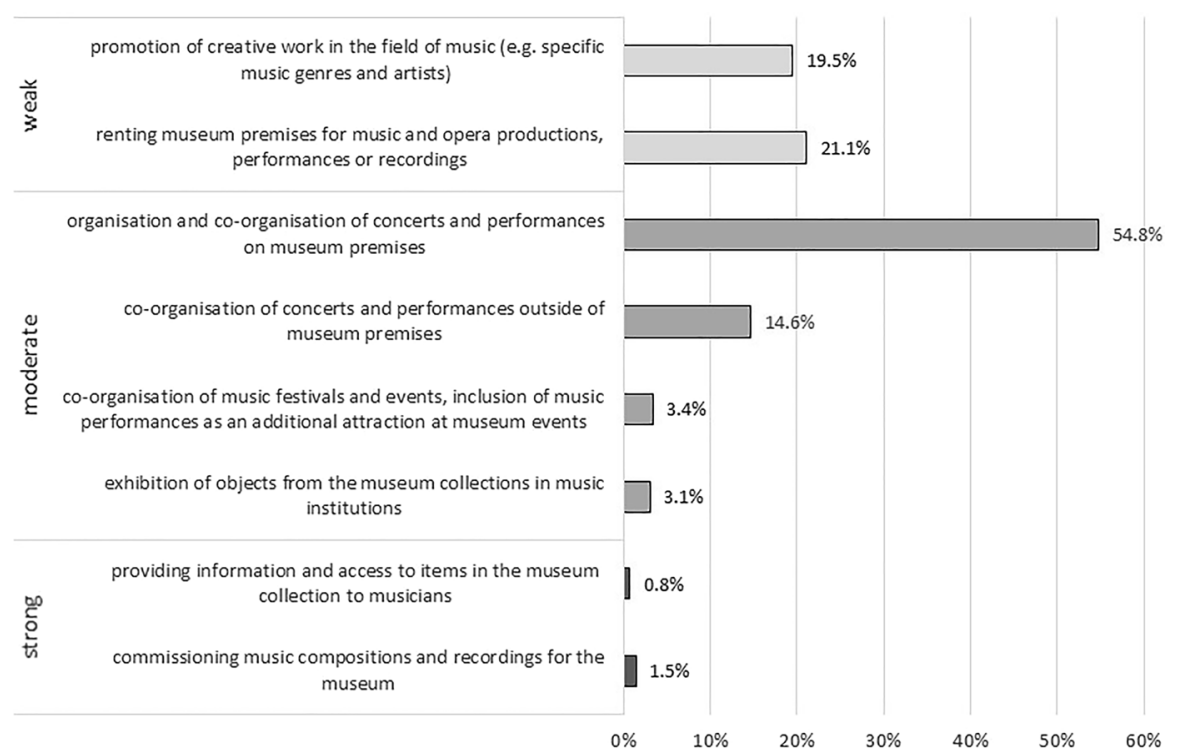

Fig. 4 Main forms of cooperation between Polish museums and the music sector. Source: authors' own elaboration of NIMOZ data, 2019

\subsection{Music}

The music sector (musicians, music institutions, and companies) appears to be a relatively frequent partner of museum institutions in Poland: two-thirds of museums report cooperation with this CCI branch. This cooperation, however, is often linked with the dissemination of existing creative content in the field of music and providing opportunities for promotion and additional earnings to the sector rather than inspiring new artistic creations and influencing their creative content (Fig. 4).

Museums in Poland host music events (concerts, performances, and festivals) on museum premises relatively often. Over half of surveyed museums organise and coorganise concerts at the museum, one in five rent museum spaces for such events, and one in seven co-organise such events outside of the museum premises. Music performances sometimes accompany major museum events (e.g. open-door days, exhibition openings). Occasionally, museums also organise or host music festivals. Depending on the museum profile and type, a relatively large number of museums engage in the promotion of creative work in the field of music, for example, for specific music genres or artists (one in five museums). Strong links are very rare, however. Very few museums (1.5\%) commissioned unique music compositions and recordings for the museum (e.g. an audio-drama as an element of a museum installation or a unique music recording commissioned as part of the museum's promotion activities). Rarely (0.8\%) do they specifically promote and provide information and access to interesting items in the museum collection that could inspire contemporary music endeavours (e.g. the possibility to perform on historic instruments or providing access to historic music recordings). 


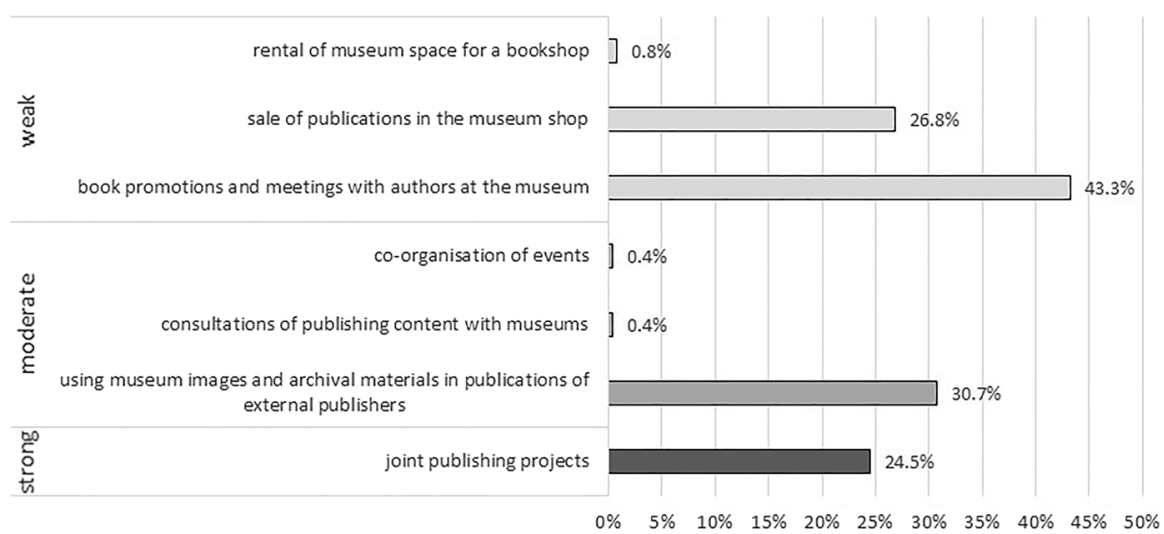

Fig. 5 Main forms of cooperation between Polish museums and the book and publishing sector. Source: authors' own elaboration of NIMOZ data, 2019

\subsection{Books and the publishing industry}

Museums in Poland rather frequently cooperate with firms and professionals in the book and publishing industry (Fig. 5).

Some of these links are weak. Two in five museums are venues or co-organisers of book promotions and meetings with book authors at the museum. One in four offer the possibility to purchase books in the museum shop. In rare instances, museums also rent space for a bookshop. Such cooperation enriches what museums have to offer their visitors, but again, this is mainly linked with the promotion, dissemination, and sale of already-produced publications ('ready'/ 'final' products of the book industry). Moderate links with the publishing sector in terms of potential knowledge spillovers are also present: almost one-third of museums report providing opportunities to use images and archival materials from the museum in publications by external publishers. One-fourth of museums, a non-negligible number, report joint publishing projects with commercial publishers, potentially a strong link. This may be due to a particular circumstance: most Polish museums are themselves part of the industry, acting as publishers of books and journals. In 2018, 62.8\% of Polish museums issued their own publications, and although the average number of books published in a year was small (5), the maximum number was as high as 45 (NIMOZ 2019). ${ }^{12}$ Moreover, three museums reported having their own printing units (printing of books, posters, and promotional materials). Whether the interactions reported are just between the staff of commercial publishing companies and the staff of museum publishing units or whether they involve exchanges of information and the development of content in direct cooperation with curators and other specialist staff makes a difference in terms of knowledge spillovers. As such fine distinctions

\footnotetext{
12 Sales of books published by museums are relatively limited because apart from guidebooks and illustrated books on major museums, they usually publish specialist scientific publications.
} 


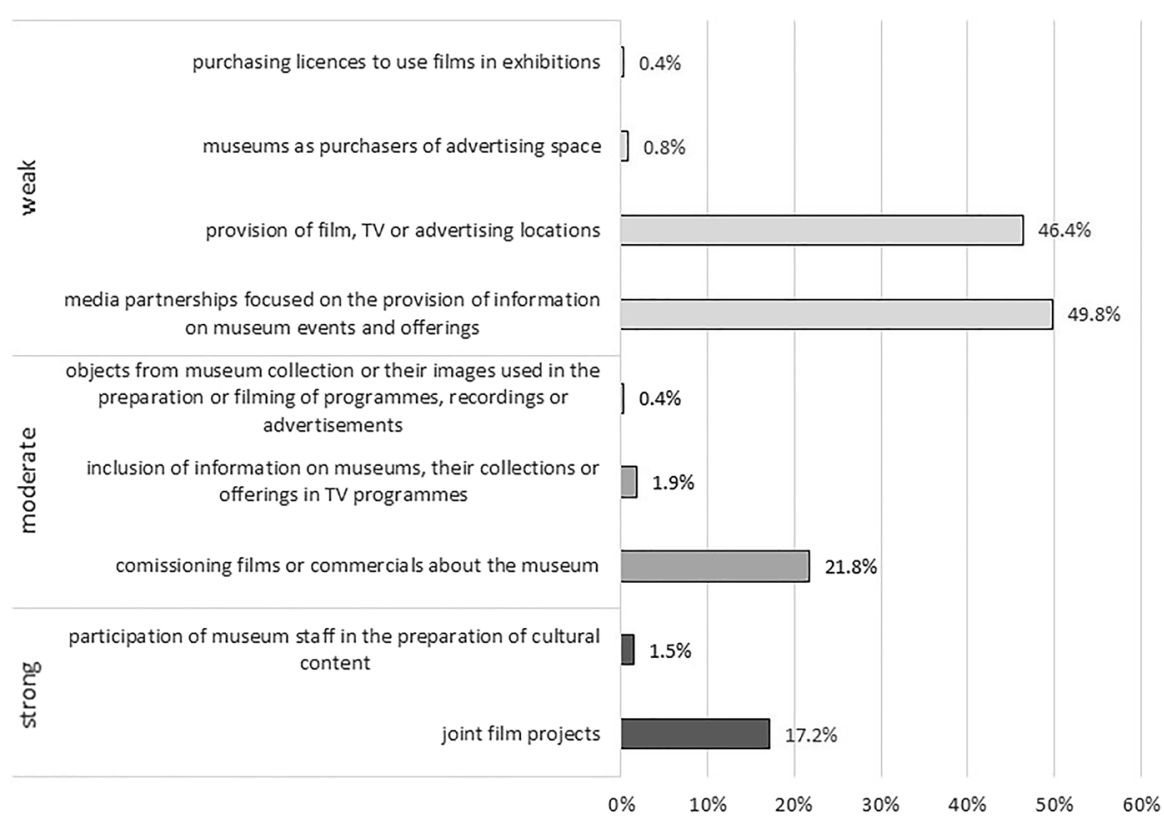

Fig. 6 Main forms of cooperation between museums and advertising, TV, and film sectors. Source: authors' own elaboration of NIMOZ data, 2019

were not included in the survey question, joint publishing projects might merely be collaborations focused on the distribution of creative content already produced by museums, which would not entail significant knowledge spillovers. More insight into the nature of these projects is therefore necessary to understand whether those reported are all strong links.

\subsection{Film, TV, and advertising companies}

Most Polish museums cooperate in some way with firms and institutions in the advertising, TV, and film industries. Moreover, one-fifth of museums report longterm, regular cooperation with this CCI branch (Fig. 6).

However, the dominant links are either media partnerships focused on the provision of information on museum activities, whereby these industries use creative content supplied by museums for promotion among potential visitors $(49.8 \%$ of institutions that participated in the survey), or pertain to the use of museum spaces as TV, film, and advertising locations ( $46.4 \%$ of museums). This second type of connection may impact the creative content produced, but it is not usually encouraged by museums due to conservation concerns. In a few cases, museums act as direct buyers of creative content already produced by the sector (e.g. purchasing licences to use films in exhibitions) or purchase advertising spaces. Moderate links occur when museums commission films or commercials about the museum or cooperate with TV stations in the production of TV programmes including museum venues, information on museum collections, or objects 


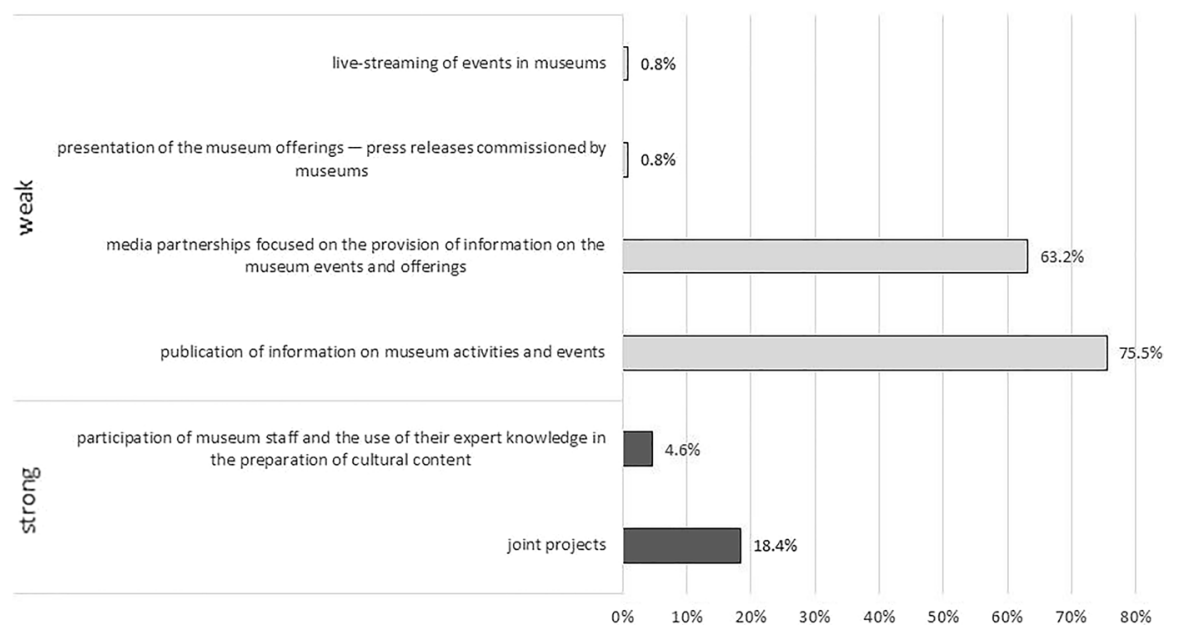

Fig. 7 Main forms of cooperation between museums and radio stations, the press, and internet portals. Source: authors' own elaboration of NIMOZ data, 2019

from the museum collections, but this type of cooperation is rarer than weak links (one in four respondents). Among the strong links, the share of museums having joint film projects with these CCIs is $17.2 \%$, while drawing on the expert knowledge and participation of museum staff in the preparation or filming of TV programmes is rarely reported $(1.5 \%)$.

\subsection{Radio stations, the press, and internet portals}

Four in five museums cooperate with radio stations, the press, and internet portals. Most of this cooperation is again focused on making information on museum activities and events available to the general public $(75.5 \%$ of museum institutions reported this type of cooperation) or media partnerships similar in scope (almost two-thirds of institutions). In selected cases (only two in the analysed sample), the cooperation involves the live streaming of events (e.g. concerts) at the museum (Fig. 7).

Forms of cooperation that are likely to generate knowledge spillovers and involve stronger collaboration in the development of creative content are not as common. Joint projects such as radio programmes, regular newspaper articles on selected topics, or the co-organisation of competitions for radio, press, and internet portals involve $18.4 \%$ of the sample. The participation of museum staff in the generation of creative content (expert commentary and scientific consultations for programmes and the press, or for internet pages) is reported by very few museums (4.6\%). 


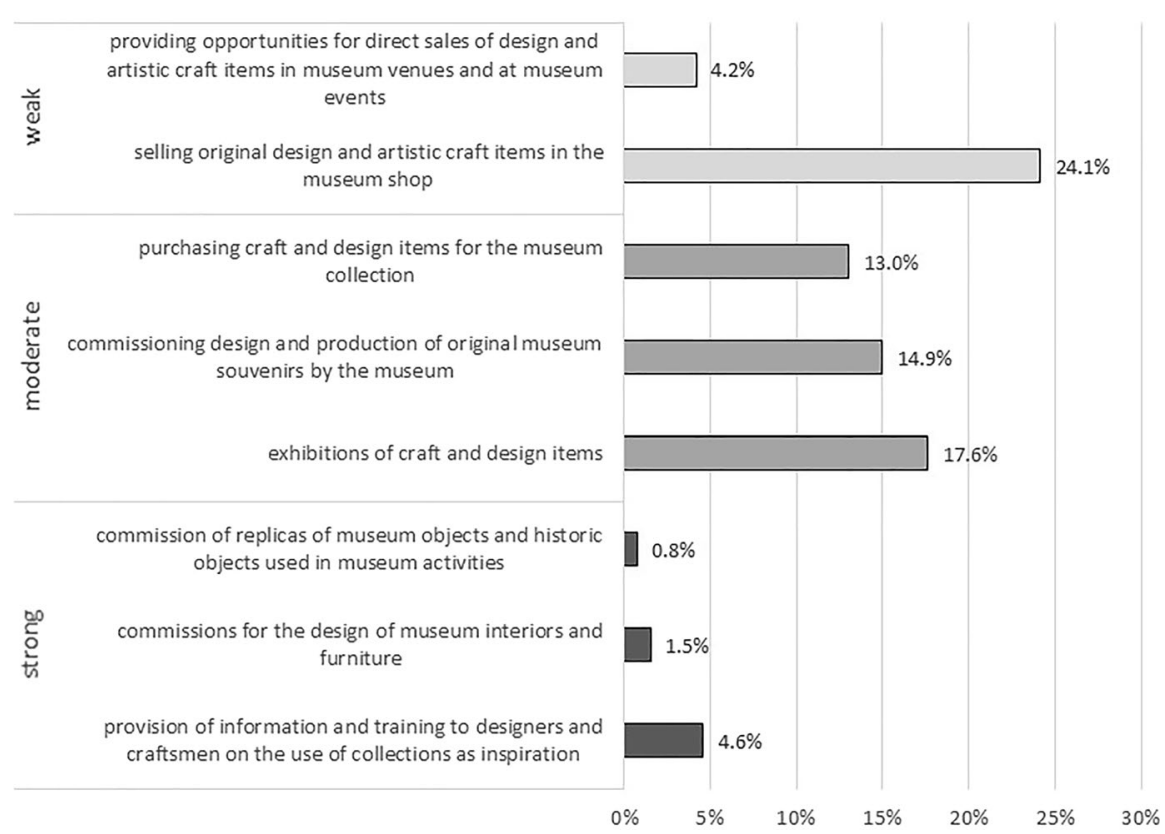

Fig. 8 Main forms of cooperation between Polish museums and the design, fashion, toy and artistic crafts sectors. Source: authors' own elaboration of NIMOZ data, 2019

\subsection{Design, fashion, artistic craft, and toy companies}

Cooperation between museums and the design and artistic crafts sector most frequently pertains to forms of interaction focused on the dissemination and promotion of already designed and produced artistic crafts and designer items (Fig. 8).

Museums may provide opportunities for the direct sale of such items either in the museum shop (almost one-fourth of museums), directly in museum venues (e.g. seasonal stalls), or during museum events, in particular fairs and outdoor events ( $4.2 \%$ of museums participating in the survey). Museums also act as gatekeepers for the crafts and design sector, as organisers of exhibitions of craft and design items (one in six museums) or as buyers of items for the museum collection (one in eight museums). Among other moderate links, the commissioning of products such as souvenirs designed specifically for the museum (one in seven museums) should be mentioned. Strong links are not so common. The provision of information and training on the potential of museum collections as inspiration for design and contemporary artistic crafts was reported by only $4.6 \%$ of Polish museums. ${ }^{13}$ According to the survey, designers and craftsmen are also rarely involved in the development

\footnotetext{
13 Design competitions organised or co-organised by some more innovative museums in Poland, especially those connected with contemporary designers drawing inspiration from museum collections or venues, though not reported in the survey, could be understood as a part of the same trend.
} 
of exhibition interiors and layouts or the design of museum furniture, replicas of museum objects, and objects used in museum activities (e.g. clothing for museum exhibitions).

\section{The need to reassess museums' contributions to innovation through their traditional missions}

Cerisola (2019) claims that while the industry-based approach to creativity and development has found little support in the data, the occupational approach (by which more creative professionals, no matter which industry they are employed in, play a role in stimulating innovation and growth) finds confirmation in many empirical contributions (for a survey, see also Marrocu and Paci 2012). ${ }^{14}$ The more recent ones (Marrocu and Paci 2012) correctly control for human capital, ${ }^{15}$ and some of them find that even non-technical, arts-related creatives enhance innovation if there is interaction with STEM professionals, i.e. those having jobs requiring the use of science, technology, engineering, and mathematics as main tools (Rodríguez-Pose and Lee 2020).

How do museums fit into this discourse? Clearly, as important institutions in informal education, they might induce their visitors to develop the type of creative attitude (problem creation and solving) characterising both STEM and artistic professionals. Cerisola (2019) finds that heritage has a positive impact on both artistic and scientific creativity. Through this impact, heritage also qualifies as a driver of local growth - probably because highly creative minds are associated with a greater ability to innovate. Though museums are not considered in the analysis, they often act as mediators of cultural heritage through their education mission. The statistical significance of the heritage variable may then be read as indirect evidence of some importance of the educational role of museums for innovation, through the mediating role of diffuse creativity. Finally, a recent contribution to the literature on cultural participation has found that consuming the services of museums and archaeological sites impacts the very formation of human capital, one of the fundamental drivers of growth and development. Using data on Italian regions and sound econometric methodologies, Crociata et al. (2020) show that exposure to heritage induces a higher probability of achieving tertiary education and attending lifelong learning programmes.

It is therefore likely that a museum can contribute to making its community more innovative mainly through its role as an education agency. The strength of this contribution depends on the character and contents conveyed by its educational programmes. Museums can also contribute to innovation in education, and their close relationship with schools may help spread innovative educational strategies.

\footnotetext{
14 The idea that the allocation of talents is relevant for growth was first proposed by Baumol (1990) and Murphy et al. (1991).

15 The earlier version of this literature (Florida 2002) was heavily criticised because of the lack of this fundamental control (Glaeser 2005).
} 


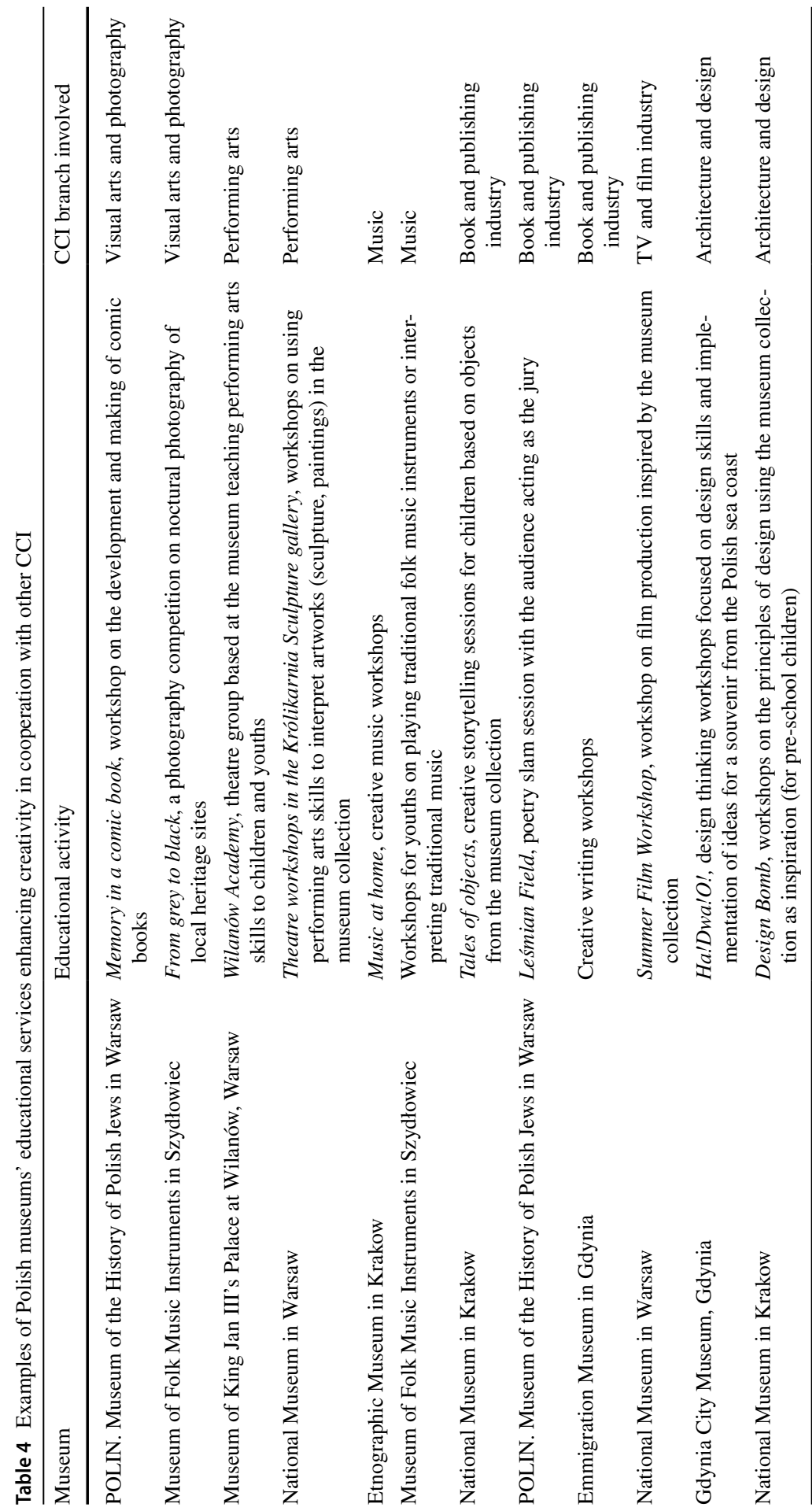


If innovation in education makes education more effective, this may be a powerful indirect way to support innovation in a community and hence its economic success and resilience, provided that the content conveyed and attitudes encouraged help innovative products and processes emerge. While science museums are at the forefront in this human capital enhancement agenda, art museums do not lag behind, as numerous case studies have shown.

Clearly, CCIs may play a role in making museum education strategies more effective. In the last two decades, the digital revolution and cooperation with firms in the IT sector has impacted museums profoundly (Bautista 2014; Borowiecki and Navarrete 2017), especially in terms of the way they function and communicate with their audiences, and this has often implied relations with CCI firms as well. Using videos, augmented reality, or videogames may make museum education better (although there are also cases of museum Disneyfication that go in the opposite direction). In this sense, focusing on the solid arrow of Fig. 1 probably makes more sense than looking at the dashed one. Table 4 illustrates some examples referring to Poland (see also Murzyn-Kupisz and Działek 2015):

As for museums' conservation activities, the knowledge spillover effects that occur when these are shared with other institutions (firms, universities) in backward supply linkages may be important (De Miguel Molina et al. 2019a, b), as the numerous scientific projects on innovative techniques originating from challenging restoration works testify. Moreover, the exhibition mission may drive innovation when associated with positive externalities in backward supply linkages. Technical sponsorships are often motivated not just by visibility (association with a well-known museum brand) but also by the fact that museum demand often poses new, interesting challenges and problems for the provider, inducing firms to improve their products (e.g. lighting, showcases, alarm systems).

\section{Conclusions}

In this paper, we propose a re-discussion and re-valuation of the role museums can play in fostering innovation. By doing so, we add to the growing body of literature on the diverse aspects of the museum-innovation nexus. We argue that the mediating role of other CCIs in channelling museums' stimulation of innovation is likely to be overrated. To illustrate our point, we propose a categorisation of relations between museums and the other CCIs according to their potential in terms of knowledge spillovers from the former to the latter. We then test this conceptual framework by applying it to Poland, a national context where the role of museums in regional and local development has been increasingly recognised in recent years and for which a unique dataset on the types of relations formed between museums and the other CCIs is available. We discover that despite their diversity, relations between museums and other CCI firms and institutions that qualify as poor in terms of their potential for innovation enhancement (weak links) greatly outnumber those rich in knowledge spillovers.

The fact that in recent years museums have often been encouraged by policymakers to foster relations with the other CCIs in hopes of both innovation- and 
economic-related outcomes (OECD-ICOM 2019) has put a lot of stress on museums (Selwood 2009). Considering their limited human and financial resources, these demands often leave them less time and opportunities to properly rethink and develop their core activities such as conservation, research, and education. Based on our analysis, we argue that inducing museums to focus on relations with the CCIs is not necessarily desirable or effective. Considering museums as actors of innovation may make sense, but perhaps more for their traditional missions-and especially education-than for inspiring firms and institutions in the cultural and creative industries. Generally, incentivising collaboration between the CCIs and museums is not an appropriate innovation policy in itself and may even result in museums mainly engaging in relationships that are poor in positive externalities. The distinction we propose between weak, moderate, and strong links between museums and CCIs calls for a selective consideration of these exchanges and may help policymakers single out the types of interactions with some real potential in this respect.

The conclusions presented in this study are based on data that pertains to a specific post-socialist context: a country in Central Europe. While in Poland we do not find frequent strong links between museums and CCIs, it is possible that in some other countries this is indeed the case. The taxonomy of links between museums and CCIs that we propose should therefore be further tested and applied in other cultural and national contexts. It may be that the potential for innovation stemming from cooperation between museums and the CCIs is greater in some countries than others, depending on core-periphery relations, a given country's overall level of development, and the importance of CCIs in its economy. It would also be interesting to take into account potential differences in the quantity and quality of links between museums and CCIs according to museum reputation (superstar and major museums versus other), the size of their collections, ownership and organisational model, location (major cities versus more peripheral locations), or museum type (e.g. openair museums, historic houses and palaces, technology and science museums).

Some other important limitations of the dataset used for the present analysis and which could be addressed in future research should also be mentioned. First, the Polish museum survey did not include explicit questions regarding cooperation between museums and the architecture and computer games sectors, while some CCI branches were considered jointly (e.g. under the broad heading of 'design'). Second, the survey provides the perspective of museums, reflecting museum managers' opinions on the existence and frequency of links and does not provide direct information on the precise nature of such links and their assessment from the point of view of CCI firms. Such information could be obtained if a similar survey was performed among CCI firms and supplemented with qualitative research (e.g. interviews on innovation with particular CCI firms and museum employees).

Nonetheless, our findings have two important policy implications. First, public support for cooperation between museums and other CCIs (e.g. via manuals, technical and organisational assistance, incentives, or grants) should be selective and based on a more in-depth consideration and assessment of the quality of links established and strengthened thanks to such support. Partnerships and relations that are more likely to generate stronger knowledge spillovers should be encouraged if the aim is to foster innovation in the CCIs: for instance, cooperation involving museum 
collections as a source of inspiration and basis for new creative content or new aesthetic, organisational, and technological solutions. While this cooperation might help CCI firms innovate more, policymakers must also be aware that their support is not guaranteed to have an impact on the innovation rate in the wider economy. In fact, the evidence on the exportability of innovation from the CCIs to other industries is inconclusive.

Secondly, core museum activities such as conservation, research, and especially education should be included in the analysis of museum impacts on innovation. These traditional missions are worthy of a more in-depth investigation from the point of view of the positive externalities they produce and consequent increases in innovativeness. Museum educational activities and services are a particularly underrated transmission channel, and other CCIs may sometimes help museums contribute to innovation through these. As a matter of fact, one could also consider the different interactions between museums and CCIs from the point of view of the knowledge spillovers produced by CCIs and impacting museum educational services.

In this perspective, the analysis presented here, distinguishing between various types of links between museums and CCIs in terms of the frequency and strength of knowledge spillovers, could be extended to relations between other cultural institutions (for instance, performing arts institutions) and the CCIs. Rather than assessing just their quantity, it would be interesting to take into account their quality-intensity (occasional, long-term) and innovation potential (weak, moderate, or strong). In fact, the benefits of infra-CCIs relations are too often taken for granted, whereas their presence should be investigated, both conceptually and empirically, in a more rigorous way.

\section{Appendix: Do museums foster innovation in their role as art market gatekeepers?}

An important aspect of museum management of collections is acquisitions, and museums often exhibit artworks not pertaining to their collections. These activities may see museums interact with artists, who can be conceived as SMEs within the CCIs. There is a specificity in these relations pertaining to the gatekeeping role museums play in the art world. A question to consider is whether museums foster innovation in art through the effect of their selection of artists and artworks.

As the value of artworks is unknown both to buyers and to sellers, the role of experts as gatekeepers of the art market serves the purpose of reducing market uncertainty (Powell 1990; Yogev 2010). Museums are part of the gatekeepers community. In fact, when museums buy or exhibit art, living artists may be involved. Musealisation is, for a contemporary artist, the ultimate recognition of the cultural and economic value of her or his work.

Do museums, in their role as gatekeepers, foster innovation in contemporary art? A positive answer must not be taken for granted. First of all, a network of experts acting as gatekeepers to a market usually agree on the selection criteria to adopt, and innovativeness may not be one of these, as history shows. For instance, in Eastern 
Europe an icon used to be judged to have more artistic value the more adherent it was to predefined models, rather than for its innovative features.

Yet it is true that since the end of the Middle Ages innovativeness has been considered a positive aspect of new art in Western civilisation. In today's globalised world, the idea that we should value art primarily for its ability to give new insights into human understandings of the world and for its use of new languages in doing so has spread from Western countries to almost everywhere. The ecosystem of a gatekeepers' community may make mistakes in judgement at times, and since path dependence is an important aspect of value creation in art markets (Bonus and Ronte 1997), this is indeed a problem - unlike in science, sudden and stark reversals of an artist's fortunes are not to be excluded. Yet these reversals are not the rule, and this comes from the very expertise of gatekeepers: exactly because they know a great deal about already existing artistic expressions, they can tell whether some artwork is new in conception or not.

Nowadays, it is often the most innovative artist who survives the scrutiny of art gallerists, curators, and museums, but is it this scrutiny per se that stimulates innovation or is it the competition for art lovers' attention, while gatekeepers simply act as certifiers of innovation? In this second hypothesis, clearly their role in stimulating innovativeness is, so to speak, of a second order of relevance.

To understand if this is the case, it is essential to understand that gatekeepers are not all the same and they interact with artists in different ways and with different degrees of intensity. As Yogev (2010) clearly illustrates, art supply is subject to a first screening by art gallerists and curators. These act as talent scouts, and their closeness to the artists they select allows them to stimulate their inspiration in a selective way, i.e. privileging those aspects of it that are most innovative, and respondent to the requirements of the gatekeepers' networks. Museums are the protagonists of a second-round selection taking place sometime later. They mostly interact with art galleries; their interactions with artists are often limited, especially in the case of the purchase or exhibition of previously created artworks. Within the ecosystem of gatekeepers, museums then act mostly as providers of credibility for art galleries and artists. Even in a context such as today's art market, where innovation is considered an important selection criterion, their stimulus to innovation in art is of a second-order magnitude: vis-à-vis innovation, they mostly act as certifiers, not as catalysts. Given these considerations, and also taking into account that we are not able to differentiate between the purchase/exhibition of previously created artworks and commissioned ones, we propose categorising relations in which a museum plays a role as a market gatekeeper as moderate links.

\section{Acknowledgement None.}

Funding Open access funding provided by Università degli Studi di Brescia within the CRUI-CARE Agreement. Research funding was provided by Narodowe Centrum Nauki (Grant No. UMO-2018/31/B/ HS4/02961).

Availability of data and materials The datasets analysed for the current study are not publicly available due to restrictions imposed by its originator, the Polish National Institute for Museums and Public Collections. 
Code availability NA.

\section{Declarations}

Conflict of interest The authors declare no conflict of interest.

Open Access This article is licensed under a Creative Commons Attribution 4.0 International License, which permits use, sharing, adaptation, distribution and reproduction in any medium or format, as long as you give appropriate credit to the original author(s) and the source, provide a link to the Creative Commons licence, and indicate if changes were made. The images or other third party material in this article are included in the article's Creative Commons licence, unless indicated otherwise in a credit line to the material. If material is not included in the article's Creative Commons licence and your intended use is not permitted by statutory regulation or exceeds the permitted use, you will need to obtain permission directly from the copyright holder. To view a copy of this licence, visit http://creativecommons.org/licen ses/by/4.0/.

\section{References}

Bakhshi, H., \& McVittie, E. (2009). Creative supply-chain linkages and innovation: Do the creative industries stimulate business innovation in the wider economy? Innovation, 11(2), 169-189

Bakhshi, H., Edwards, J. S., Roper, S., Scully, J., Shaw, D., Morley, L., \& Rathbone, N. (2015). Assessing an experimental approach to industrial policy evaluation: Applying RCT + to the case of Creative Credits. Research Policy, 44(8), 1462-1472

Barro, R. \& Sala-i-Martin, X. (2003). Economic growth. Cambridge, MA and London: MIT Press.

Baumol, W. J. (1990). Entrepreneurship: Productive, unproductive and destructive. Journal of Political Economy, 43, 893-921

Bautista, S. S. (2014). Museums in the digital age. Plymouth: Altamira Press.

Bonus, H., \& Ronte, D. (1997). Credibility and economic value in the visual arts. Journal of Cultural Economics, 21, 103-118

Borowiecki, K., \& Navarette, T. (2017). Digitization of heritage collections as an indicator of innovation. Economics of Innovation and New Technology, 26(3), 227-246.

Cerisola, S. (2018). Multiple creative talents and their determinants at the local level. Journal of Cultural Economics, 42, 243-269

Cerisola, S. (2019). Cultural heritage, creativity and economic development. Cheltenham-Northampton: Edward Elgar Publishing.

Chapain, C. \& Stryjakiewicz, T. (2017). Introduction - Creative industries in Europe: Drivers of (new) sectoral and spatial dynamics. In C. Chapain, T. Stryjakiewicz (Eds.), Creative industries in Europe. Drivers of new sectoral and spatial dynamics (pp. 1-15). Cham: Springer.

Crociata, A., Isoardi, I., Agovino, M., \& Sacco, P. L. (2020). A missing link? Cultural capital as a source of human capital: Evidence from Italian regional data. The Annals of Regional Science, 64, 79-109

Cunningham, S., Silver, J., \& McDonnell, J. (2010). Rates of change: Online distribution as disruptive technology in the film industry. Media International Australia, 136(1), 119-132

Dalle Nogare, C., \& Scuderi, R. (2020). Branching out beyond the core: Museums hosting events. Annals of Tourism Research, 82, 102773

DCMS - Department for Culture, Media \& Sport (1998). Creative industries mapping document. London: DCMS.

DCMS - Department for Culture, Media \& Sport (2016). Creative industries economic estimates methodology. London: DCMS.

De Miguel Molina, B., Hervás-Oliver, J.-L., \& Boix Domenech, R. (2019a). Understanding innovation in creative industries: Knowledge bases and innovation performance in art restoration organisations. Innovation, 21(3), 421-442.

De Miguel Molina, B., Boix Domenech, R., \& de Miguel Molina, M. (2019b). Analysing innovation in museums through qualitative comparative analysis. Knowledge Management Research \& Practice, 17(2), 213-226. 
European Commission (EC) (2010). Unlocking the potential of cultural and creative industries. Green paper, Brussels, COM(2010) 183 final, https://op.europa.eu/en/publication-detail/-/publication/ 1cb6f484-074b-4913-87b3-344ccf020eef/language-en. Accessed 19 June 2020.

European Commission (EC) (2016). Boosting the competitiveness of the cultural and creative industries for growth and jobs. Brussels, EASME/COSME/2015/003. https://ec.europa.eu/growth/content/ boosting-competitiveness-cultural-and-creative-industries-growth-and-jobs-0_en. Accessed 19 June 2020.

Florida, R. (2002). The rise of the creative class... and how it's transforming work, leisure, community and everyday life. New York: Basic Books.

Galloway, S., \& Dunlop, S. (2007). A critique of definitions of the cultural and creative industries in public policy. International Journal of Cultural Policy, 13(1), 17-31

Glaeser, E. (2005). Review of Richard Florida's the rise of the creative class. Regional Science and Urban Economics, 35, 593-596

Hartley, J., Potts, J., Cunningham, S., Flew, T., Keane, M., \& Banks, J. (2013). Key concepts in creative industries. London: Sage.

Kasprzak, R. (2017). Creative industries in the Polish economy: Growth and operating conditions. In C. Chapain, T. Stryjakiewicz (Eds.), Creative industries in Europe. Drivers of new sectoral and spatial dynamics (pp. 151-176). Cham: Springer.

Innocenti, N., \& Lazzeretti, L. (2019). Do the creative industries support growth and innovation in the wider economy? Industry relatedness and employment growth in Italy. Industry and Innovation, 26(10), 1152-1173

KEA European Affairs (2006). The economy of culture in Europe. Brussels: European Commission, Directorate-General for Education and Culture.

KEA European Affairs (2019a). Impulse paper on the role of cultural and creative sectors in innovating European industry. Brussels: European Commission.

KEA European Affairs (2019b). Market analysis of the cultural and creative sectors in Europe. A sector to invest in. Brussels: European Investment Fund, KEA, European Affairs.

Lee, N., \& Rodríguez-Pose, A. (2014). Creativity, cities and innovation. Environment and Planning A, 46, 1139-1159

Marrocu, E., \& Paci, R. (2012). Education or creativity: What matters most for economic performance? Geography, 88(4), 369-401

Mikić, H. (2012). Measuring the economic contribution of cultural industries. A review and assessment of current methodological approaches. Montreal: UNESCO Institute of Statistics.

Müller, K., Rammer, C., \& Trüby, J. (2009). The role of creative industries in industrial innovation. Innovation, 11(2), 148-168

Murphy, K. M., Shleifer, A., \& Vishny, R. W. (1991). The allocation of talent: Implications for growth. The Quarterly Journal of Economics, 106(2), 503-530

Murzyn-Kupisz, M. \& Działek, J. (2015). Libraries and museums as breeding grounds of social capital and creativity: potential and challenges in the post-socialist context. In S. Warren, P. Jones (Eds.), Creative economies, creative communities. Rethinking place, policy and practice (pp. 145-169). Farnham: Ashgate.

Murzyn-Kupisz, M. (2017). Socio-economic aspects of museum operations: Employment, income and expenditure in museums. In Museums in Poland. Reports based on data from the Museum Statistics project (2013-2015) (pp. 79-112). Warsaw: NIMOZ.

Murzyn-Kupisz, M., Hołuj, D., Działek, J., \& Gorczyca, K. (2019). Museums and local governments in Poland: Partners in local development? Museum International, 71, 28-45

Northern Ireland Museums Council (2020). Museums and creative industries toolkit. Holywood: Northern Ireland Museums Council, https:/www.nimc.co.uk/what-we-do/guidance-and-information/ museum-and-creative-industries-toolkit. Accessed 19 June 2020.

NEMO (2018). Museums and creative industries. Caste studies from across Europe. Berlin: NEMO.

NIMOZ (2019). Museums in 2018. Warsaw: NIMOZ.

OECD. (2019). Museums and local development in Poland. OECD Publishing.

OECD/Eurostat (2005). Oslo manual: Guidelines for collecting and interpreting innovation data, 3rd Edition. Paris-Luxembourg: OECD Publishing, Eurostat.

OECD-ICOM (2019). Culture and local development: Maximising the impact. Paris: OECD Publishing.

OECD-Eurostat (2019). Oslo manual 2018: Guidelines for collecting, reporting and using data on innovation, 4th Edition, The Measurement of Scientific, Technological and Innovation Activities. ParisLuxembourg: OECD Publishing, Eurostat. 
Petruzzelli, A., \& Lerro, A. (2020). Editorial. Technovation, 92, 102132

Potts, J., \& Cunningham, S. (2008). Four models of the creative industries. International Journal of Cultural Policy, 14(3), 233-247

Powell, W. W. (1990). Neither market nor hierarchy: Network forms of organization. Research in Organizational Behavior, 12, 295-336

Power, D. (2011). The European Cluster Observatory priority sector report: Creative and cultural industries. Luxembourg: Publications Office of the European Union.

Rectanus, M. W. (2020). Museums inside out. Artist collaborations and new exhibition ecologies. Minneapolis: University of Minnesota Press.

Rodríguez-Pose, A., \& Lee, N. (2020). Hipsters vs geeks? Creative workers, STEM and innovation in US cities. Cities, 100, 102653

Romer, D. (1996). Advanced macroeconomics. New York: McGraw-Hill.

Santoro, G., Bresciani, S., \& Papa, A. (2020). Collaborative modes with cultural and creative industries and innovation performance: The moderating role of heterogeneous sources of knowledge and absorptive capacity. Technovation, 92, 102040

Sandahl, J. (2019). The museum definition as the backbone of ICOM. Museum International, 71(1-2), 1-9

Selwood, S. (2009). Museums, galleries and the visual arts. In A. C. Pratt, P. Jeffcutt (Eds), Creativity, innovation and the cultural economy (pp. 219-240). Routledge: London, New York.

Sīmansone, I. Z., Sīmansons, R., Spuriņš, U., \& Klāsons, G. (2015). Museums and creative industries: Mapping cooperation creative toolkit. Riga: Creative Museum Riga, https://www.ne-mo.org/filea dmin/Dateien/public/Working_Group_1/Working_Group_MCI/Museums_and_Creative_Indus tries_MappingCooperation_NEMO_MCIWG.pdf. Accessed June 202020.

Statistics Poland (2018). Cultural and creative industries in 2014-2018. Warsaw: Statistics Poland.

Sternberg, R. (2017) Creativity support policies as a means of development policy for the global South? A critical appraisal of the UNESCO Creative Economy Report 2013. Regional Studies, 51(2), 336-345.

The Work Foundation (2007). Staying ahead: The economic performance of the UK's creative industries. London: DCMS.

Throsby, D. (2008). The concentric circle model of the cultural industries. Cultural Trends, 17(3), $147-164$

Throsby, D. (2010). The economics of cultural policy. Cambridge: Cambridge University Press.

Throsby, D. (2015). The cultural industries as a sector of the economy. In K. Oakley, J. O'Connor (Eds.), The Routledge companion to the cultural industries (pp. 56-69). London: Routledge.

Towse, R. (2003). Cultural industries. In R. Towse (Ed.), A handbook of cultural economics (pp. 170-176). Cheltenham: Edward Elgar.

Tschmuck, P. (2006). Creativity and innovation in the music industry. Dordrecht: Springer.

UNCAD (2010). Creative economy report 2010. Geneva: UNCTAD.

van Heerden, S., \& Bontje, M. (2013). What about culture for the ordinary workforce? A study on the locational preferences of the creative class in Prenzlauer Berg, Berlin. Journal of Urban Affairs, 36(3), 465-481.

Wikström, P. \& DeFillippi, R. (Eds.) (2016). Business innovation and disruption in the music industry. Cheltenham: Edward Elgar.

Work Foundation. (2007). Staying ahead: The economic performance of the UK's creative industries. London: DCMS.

Yogev, T. (2010). The social construction of quality: Status dynamics in the market of contemporary art. Socio-Economic Review, 8, 511-536.

Publisher's Note Springer Nature remains neutral with regard to jurisdictional claims in published maps and institutional affiliations. 